\title{
The psychoanalytic theory of anxiety and defense
}

\author{
Donald L. Carveth, Ph.D.
}

\begin{abstract}
The chronological development of Freud's theories of anxiety is reviewed in connection with the series of infantile danger-situations, the distinction between traumatic and signal anxiety, and the defenses evoked by the latter to avoid the former. The central defense of turning aggression away from the object and back against the self, thus generating the hostile superego, is emphasized. A critique of Freud's one-sided conception of danger as loss of the good is offered in light of Melanie Klein's recognition of the danger constituted by the presence of something bad. In light of the shift from topographical to structural theory additional types of anxiety are distinguished: instinctual anxiety experienced by the ego in the face of the Id; Reality anxiety in the face of the external world; moralistic anxiety in the face of the superego. While Freud failed to distinguish persecutory and reparative anxiety and guilt, Klein and her followers posited two fundamentally different layers or positions in the mind, the paranoid-schizoid and depressive or reparative positions characterized by these two types of anxiety and guilt respectively. There has been a good deal of confusion due to the widespread failure to distinguish depressive anxiety from depression: there is no depression in the depressive position because the splitting involved in depression is a paranoid-schizoid phenomenon. The existentialists remind us that not all anxiety and guilt is neurotic.
\end{abstract}

Today, when they encounter patients with anxiety or panic attacks, many psychotherapists, even psychoanalysts, often assume these symptoms are rooted rather directly in past or present trauma of some kind. But anxiety and panic often arise in the face of unwanted feelings, such as anger, rage, or sexual desire.

Many people are very intolerant and frightened of their aggressive and sexual impulses, among other feelings, and do not want to know about them. It seems they have either internalized parental rejection and disapproval of such feelings, or they have not overcome the child's equation of thoughts with deeds, fearing that if they allow themselves to become consciously aware of their aggressive and sexual wishes unacceptable and dangerous action will follow in which the self and others will be harmed and severe punishments will inevitably follow. Many adults seem not to fully grasp the fact that fantasies, feelings, impulses and emotions can become conscious and held in mind without magically producing destructive consequences. Hence, they remain fearful of their emotions and fantasies and feel there is little alternative but to bottle them upi.e., unconsciously repress them (Freud, 1915). But one of Freud's fundamental discoveries is that the repressed inevitably returns in disguised forms: symptoms, dreams, slips of the tongue, etc. (Freud, 1900; 1902). Ironically, anger is more likely to 
emerge in destructive forms when it has been denied more benign discharge through conscious feeling and fantasy or verbalization to the self or another.

Repressed anger often underlies anxiety attacks. It is as if the person unconsciously fears that their anger is coming very close to the surface and imagines that something like a volcano may be about to erupt. It is possible that such people have experienced trauma of some type in the past, but we must not forget that when we are traumatized we oftenperhaps always on some level-react with rage. Pain and frustration generally lead to aggression. Traumatized people are generally angry people who often do not want to be angry and do not want to know that they are. Often they unconsciously turn their anger upon themselves, resulting in a host of possible symptoms from depression, to masochism or psychosomatic and hysterical conditions. When their anger is close to erupting, they often have a panic attack. While I cannot claim that all panic attacks boil down to this, I think this is often an important part of the picture.

Freud's first theory of anxiety has been called the toxicological theory of anxiety in which repressed libido, frustrated sexuality, leads to a damming up of the libido (the hypothetical energy of the sexual drive). The dammed up libido was thought to turn into anxiety, as wine breaks down into vinegar. So anxiety in this early theory is a sign of frustrated sexuality. This idea is linked to Freud's notion of the so-called actual neurosis which he distinguished from the psychoneurosis. The symptoms of the actual neurosis he thought were not psychoneurotic but a direct consequence of frustrating sexual practices. They did not indicate psychic conflict but were a direct physiological consequence of incomplete or inadequate sexual discharge (Freud, 1916-17; 1933).

We know that in his personal sex life Freud had already had as many children as he wanted and had withdrawn from a good deal of sexuality with his wife out of a fear of impregnating her (Jones, 1955). Contraception was inadequate and frustrating. In this way Freud accounted for his own anxiety symptoms which he did not want to see as psychoneurotic; he attributed them to direct frustration-the so-called actual neurosis. But no one else could find evidence of the existence of the actual neurosis and, as a result, the concept fell by the wayside. One can see the concept as a manifestation of Freud's resistance to recognizing his own psychoneurosis. 
It took Freud quite a number of years to get past this early toxicological theory of anxiety as a direct result of dammed-up sexual libido. But by 1926 in Inhibitions, Symptoms and Anxiety he finally explicitly rejects this theory and reverses himself. Up until 1926 he thought that repression causes anxiety; now he acknowledges he got it backwards: anxiety causes repression. He goes on to distinguish two types of anxiety: traumatic anxiety, which he also calls automatic anxiety, on the one hand, and signal anxiety on the other. Traumatic or automatic anxiety is what happens in trauma when a person is overwhelmed and feels helpless in the face of some situation; and it is this feeling of helplessness and of being overwhelmed that generates traumatic or automatic anxiety. Freud cites, as an example not as a cause, the birth trauma. Here the infant is helpless and goes through what must be an overwhelming experience of moving through the birth canal and coming out into a cold and bright environment and having to take that first breath. The trauma of birth is not the cause but the prototype of all subsequent anxiety situations. Otto Rank (1924) went much further arguing it is not just the prototype but the root cause of later anxiety. Freud did not agree with this or with Rank's attempt to come up with a brief therapy by going directly back to the birth trauma. Freud (1926) counters with an analogy. A multi-story building is inflamed because an oil lamp was overturned in the basement. It is as if Rank believes all the firemen need to do is to go in and retrieve the overturned oil lamp and all will be well. But this ignores the fact that the whole building and all the upper floors are now in flames.

So the trauma of birth is not the cause of later neuroses, it is merely the prototype of traumatic or automatic anxiety states, which we have all experienced, because even the most devoted primary caretakers cannot be perfect. There will be frustrating delays; the infant has no sense of time so a minute can seem like hours; the infant is helpless to feed, warm, or change itself. To one degree or another we have all encountered this kind of trauma and the anxiety it generates. But with the early development of the ego the infant is able to learn to anticipate situations where this overwhelming traumatic situation of helplessness may occur. As soon as the caretaker starts to leave the room, the infant recognizes this is a situation in which it can be overwhelmed; it generates signal anxiety in the face of a danger-situation, a small amount of anxiety as a warning against the much larger quantity of anxiety, the traumatic anxiety, which threatens. The infant begins to 
defend itself by crying in an attempt to bring the caretaker back into the room. So signal anxiety is based on anticipation; it's an attempt to avoid trauma by generating a small amount of anxiety which serves as a signal to institute defensive manoeuvres to avoid the much larger amount of anxiety that comes with trauma.

Freud proceeds to enumerate a series of danger- situations or what Charles Brenner (1982) called the catastrophes of childhood. In the first year of life the danger is the loss of the object. In Kleinian terms this would mean the loss of the good part-object, the breast. This would essentially mean death because if an infant loses the primary caretaker it may die.

In the second year of life the infant's mind has evolved to the point where it is perceiving the primary caretaker not simply as a feeding thing but as a person whose love is crucial. In this way the caretaker acquires the power to train the child because the child wants to maintain the caretaker's smile and not have it replaced by a frown. Here the danger is the loss of the object's love--not just the loss of the part-object, but loss of the whole-object's love.

As we move into the third year of life, the danger becomes what Freud calls castration anxiety, the fear of loss of what for Freud was the penis but which the French psychoanalyst Jacques Lucan (2002) clarifies as the "phallus": those qualities that enable one to attract the desire of the other for, according to Lacan, one's desire is the desire of the other-that is, I desire to be desired. The phallus is not the literal penis but symbolizes that which the caretaker wants and that I wish to supply. I fear the loss of what I have that makes me desirable to my desired other. Towards the end of the oedipal phase due to fear of retaliation by the rival and guilt for hating as well as loving the rival, the child turns its aggression away from the rival and back against itself, thus acquiring a superego, for that is what the superego is: aggression turned away from the object back against the self. Once I have a superego, I face the fourth danger-situation: the fear of guilt, loss of the superego's love, a superego attack.

For Freud, the later dangers really fold back into the earlier ones; beneath the fear of the superego is the fear of castration; beneath the fear of castration is the fear of loss of the object's love,; and beneath fear of loss of the object's love is fear of loss of the object- 
which is about as close as Freud comes to proposing anything like a primary death anxiety, for loss of the object would, for the infant, be tantamount to death.

So here we have a series of danger-situations and whenever in later life I am in a situation which confronts me with any one of these dangers signal anxiety is generated so that I can begin to take steps to avoid trauma and the regressive retreat from the later to earlier and, finally, the earliest danger. Initially my superego generates some guilt. If I fail to change course in time then I am threatened with castration; and if I still fail to successfully defend myself, I may be faced with loss of the object's love. Finally, if I do not change course, I may be faced with the ultimate catastrophe: loss of the object itself.

In a whole range of situations in adult life these anxieties are stimulated and defensive steps are taken more or less successfully. The thing to notice about Freud's sequence of danger-situations is that they all concern loss of something good: loss of the part-object breast; loss of the whole-object's love; loss of the phallus; loss of the superego's love.

Loss, loss, and more loss. For Freud the danger-situation always involves loss or absence of something good, never the presence of something bad and attacking or persecutory. This is because Freud, I believe, never was able to overcome his idealization of the mother. In one place he even claims that all human relations that reach any depth are characterized by ambivalence, by both love and hate-except, perhaps, for one exception: the relationship of a mother and her son. In Freud and his Mother, Margolis (1996) suggests that Freud was never able to accept his repressed hatred for his narcissistic mother. He kept the mother on a pedestal, as a good object. There are exceptions to this; occasionally the frightening phallic mother appears in Freud's thought. But to a very large extent the mother is kept as an idealized figure, a target of oedipal desire but not very often seen as a persecutor. It was Freud's Berlin colleague, Karl Abraham, who through his studies of the Italian painter, Giovanni] Segantini (whose hatred of the mother is clearly evident in his work), came to recognize the bad persecutory mother (May, 2001). Abraham's analysand was Melanie Klein who makes both the persecutory and the ideal breast-mother central in psychoanalytic object-relations theory. Abraham and Klein add to Freud's sequence of danger situations. In addition to loss of the good there is the threatening persecutory presence of the bad part- object. 
This is not the place to go into a more detailed study of the theory of the Oedipus complex. In my review so far, I have been speaking mostly about the situation of the male child, not because of a sexist bias but because to study the differences between the female and the male situation in this area is very complex. Freud puzzled about this throughout the 1920 and wrote a whole series of papers demonstrating that there is no simple equivalence and no simple reversal of these situations. Freud refused to posit an Electra complex in the girl parallel to the boy's Oedipus complex precisely because no such parallel exists. Both boys and girls fall in love with the primary caretaker, most often still the mother. For the girl this is a same-sex object; for the boy an opposite-sex object, hence these developments are very different for the two sexes.

In the face of strong sexual and aggressive urges coming up from the id, the ego can experience anxiety and can institute defenses. When patients present with anxiety, rather than being a direct reflection of trauma of some kind, it may actually be in the face of powerful repressed feelings that are threatening to emerge into consciousness generating fear of the superego, fear of "castration," fear of loss of love, or fear of object loss altogether. All this amounts to intense signal anxiety, indicating an imminent threat of traumatic anxiety unless effective defenses can be put in place. Such anxiety indicates the power of unwanted sexual and aggressive feelings and fantasies.

But the ego can also experience anxiety in the face of the superego, which is not in my view (Carveth, 2013) a conscience but an internal hanging judge, a harsh, moralistic, highly critical internal attacker, often characterized by what Heinrich Racker (1957) called a "mania for reproaching" (p.141), exulting in finding fault, shaming and punishing. Naturally, the ego fears this kind of moralistic attack by the superego and it generates signal anxiety in such a danger situation. If I do not do something quickly, if I do not change my ways in time, I am in danger of being morally assaulted and beaten down by the superego. This is signal anxiety in the face of the superego rather than the drives.

Finally, the ego can experience anxiety in the face of reality: the rent or the income tax payment is due but there are insufficient funds in the bank. Sometimes anxiety is generated in the face of real demands, real dangers, but sometimes it is based on misapprehension or distortion: one may not be seeing reality clearly; one may in fact be rather paranoid and exaggerating the threat of attack from the outside. But whether 
reality is accurately perceived or perceived in a highly distorted way, in either case, the ego feels in danger and generates anxiety.

In the case of anxieties in the face of the so-called instincts, we have instinctual anxiety; if anxiety is in the face of the superego, we have moral anxiety-though I would rather say pseudo-moral anxiety because the superego is not essentially moral; it loves to catch you in wrongdoing not because it really cares about morality but because, being composed of id aggression turned on the self, it loves to beat you; it is governed by a pseudo-morality principle. The id is governed by a pleasure-pain principle. The ego operates according to the reality principle (Freud, 1911) but sometimes its assessments of reality are faulty and it feels unwarranted anxiety in the face of fantasy mistaken for fact.

So the poor ego is threatened on three fronts and when it generates anxiety it institutes defensive measures in order to avoid trauma. Defenses can be directed against all three fronts. When defenses are against the sexual and aggressive drives of the id, we have neurosis. When the ego is directing defenses against the superego, we have impulse disorders of various kinds-antisocial personality disorders, addictions, certain perversions - because the defenses against the superego can put it out of operation, allowing behavior that would otherwise be inhibited. When defenses are mobilized against a threatening reality, or a reality perceived as threatening, the ego's main function, reality-testing, may be compromised. Although milder defenses against threatening realities are ubiquitous, especially in childhood, when they exceed a certain limit psychosis may result.

Melanie Klein $(1946,1948)$ greatly elaborated the psychoanalytic theory of anxiety and defense through her important distinctions between two fundamentally different kinds of anxiety, persecutory on the one hand and depressive or reparative on the other, and her related distinctions between persecutory and depressive or reparative guilt. Persecutory anxiety belongs to the paranoid-schizoid position where everything is split into all-good or all-bad. (In this context "schizoid" refers to splitting, not to a personality disorder characterized by social withdrawal.)

Klein's schizoid position is also a paranoid position because the all-good or the allbad object can be projected out onto others or kept in and identified with the self. The 
projection of these contents outwards onto others is an essential feature of the paranoidschizoid position resulting in either extreme idealization (idolizations) or devaluation (demonization). Hence, in this position, life tends to be experienced as something of a jungle, a matter of kill or be killed. One may experience oneself as prey being hunted by predators. It follows that here narcissism reigns for in this apparently precarious situation one's priority is survival rather than altruistic concern for others. The kind of anxiety experienced here is anxiety in the face of the predators, persecutory anxiety in the face of real or imagined attackers. Sometimes the attackers are real; many of the more "paranoid" Jews got out of Germany in time. Some people suffer from insufficient paranoia and their reality-testing is hampered as a result. Some are overly paranoid. In the PS position anxiety is of a persecutory and therefore of a narcissistic type.

As we move into the depressive (or what I prefer to call the reparative) position, the leading anxiety is depressive anxiety-not to be confused with depression. There is a good deal of misunderstanding of Klein in this area; she calls it the depressive position not because depression is found here but because here is where depressive anxiety occurs. By depressive anxiety we mean my fear that my attacks on what I viewed in PS as an allbad object are irreparable. As I move into the depressive/reparative position I overcome splitting and begin to see that the object that I thought was an all-bad persecutor is also an object containing goodness. Have I destroyed it? Is there still time to rescue and repair it? Depressive anxiety is anxiety in the face of my own destructiveness that may have done great damage. I am urgently seeking to repair the damage that I have or imagined I have done in my paranoid-schizoid blindness.

Donald Winnicott (1963) helpfully renamed depressive anxiety the capacity for concern. As we move from PS into D, we acquire this capacity; we move from part-object relations to whole-object relations. In Freud's terms we achieve ambivalence: PS is preambivalent whereas $\mathrm{D}$ is an ambivalent position that leads to the capacity for concern for the object and attempts to make reparation for damage done.

Just as these are very different types of anxiety, so there are two very different types of guilt. In the paranoid-schizoid position we have persecutory or punitive guilt in which I simply flagellate myself for my sins or crimes. I personally believe that persecutory guilt and shame are pretty much the same thing: they are both narcissistic states and of little 
or no use to the one injured. But if I move into the depressive position, I become capable of reparative guilt, in which case I drop my cat-o'-nine-tails and the self-flagellation, pick up my first-aid kit and get busy bandaging the injured other. In PS we are immersed in ourselves, but as we move into $\mathrm{D}$ we discover the reality of the other and develop some degree of concern, caritas, towards the other.

Whereas Freud recognized mainly punitive guilt and, hence, bemoaned its buildup in civilization, Klein recognized depressive guilt driving toward reparation as well. This enables us to see that if we have too much persecutory guilt and shame in civilization, we have far too little reparative guilt and reparation.

In my own writings over the last twenty years I have associated the superego with persecutory anxiety and persecutory guilt and shame; and associated the conscience with the capacity for concern, depressive anxiety, and reparative guilt. Against Freud's (1923) decision to merge them, I argue conscience is quite distinct from superego: conscience reflects concern for the other, while the superego is a cruel inner attacker. Conscience arises from early experience with the nurturer who fed us and kept us alive; it's based on an identification with the nurturer. The superego, as Freud explained, is id aggression turned against the self. Melanie Klein found this process at work far earlier than Freud thought, in the early pre-oedipal rather than at the end of the oedipal phase. Very early on we start turning aggression against ourselves and we identify with the aggressor. This is the early persecutory superego.

I have argued that with the rise of what Christopher Lasch (1979) called the "culture of narcissism" there began a flight from guilt both in society and in psychoanalysis. Along with the neo-liberal push for privatization and attack on regulators, there was flight from the superego in society and in the psychoanalytic thinking it shaped. All this was paralleled by a growing preoccupation with shame. The last thing a narcissist wants to face is mature (reparative) guilt; at the same time he is very prone to suffer from persecutory guilt or shame. Depressive or reparative guilt is a far more mature emotion reflecting concern not just for the self but for the other. Shame is a narcissistic state in which I am painfully focused, not on the other but on the horribly bad or inadequate nature of my self. Over the past decade guilt and the superego have begun to enjoy something of a revival in psychoanalysts, a rediscovery of the role of persecutory guilt and 
the superego in psychopathology (Akhtar, 2013; Barnett, 2007; Carveth, 2013; Frattaroli, 2013; Hughes, 2008; Reiner, 2009).

Existentialist philosophers and psychotherapists have contributed importantly to our understanding in this area. Søren Kierkegaard $(1843,1844,1849)$ from a Christian perspective and Martin Buber (1965) from a Jewish perspective remind us that not all anxiety and guilt are neurotic. They make a distinction between neurotic anxiety and guilt on one hand and existential anxiety and guilt on the other. Freud has told us much about neurotic anxiety in the face of the drives, in the face of the superego, and in the face of external reality. But in addition to all this there is what Kierkegaard calls existential anxiety - the anxiety that is intrinsic to the human condition as such, that all human beings suffer from, defend against, or preferably learn how to bear. This is the anxiety of freedom. As existentialists, both Kierkegaard and Buber share with the Abrahamic religions a view of the human being as unlike all other creatures in being blessed and burdened with freedom. For Erich Fromm (1941) freedom is something people often seek to escape, ready to lay down its burden at the feet of controlling and domineering others. For Jean-Paul Sartre (1943), freedom is less something we prize or seek than a state that we are condemned to have to suffer and that we constantly deny through myriad forms of bad faith. We suffer existential anxiety because we are free and because we have to constantly decide what is right and what is wrong. If we seek to escape the anxiety of freedom we wind up, for Sartre, embracing a life of bad faith or, for Kierkegaard, a shutin life. In fact, for Kierkegaard, our attempts to escape from existential freedom and anxiety have the end result of generating neurotic anxiety. A great deal of neurotic anxiety arises from our unwillingness to face existential anxiety. It is interesting that psychoanalysts who follow Melanie Klein and Wilfred Bion tend to agree: For Bion (1962) psychopathology is rooted in an early decision to evacuate pain and frustration rather than to learn how to bear them. This is essentially Kierkegaard's position: what we have to do in the face of the anxiety of freedom is bear that anxiety and move ahead and make decisions and move into life despite our anxiety. The escape from existential anxiety leads to neurosis.

Martin Buber (1965) distinguishes real guilt from mere guilt feelings. Neurotics can feel very guilty over trifles. Even if we assume the basis for this irrational guilt is 
unconscious, its unconscious foundation may lie not in fact but in phantasy. It may involve an imaginary rather than a real crime or sin. A woman suffered lifelong selftorture for the imaginary crime of killing her sister. But at the same time her guilt was fed by the fact that, although innocent of murder, she had been gratified by her sister's death. Part of the psychoanalytic task is to sort out how much of our guilt arises from real crimes and how much from imaginary ones. Many of the latter involve magical thinking in which a destructive wish, feeling or fantasy is felt to be a destructive act. Many psychoanalysts think that we should only feel guilt in relation to harmful acts, not for hostile, destructive thoughts and feelings. But while guilt arising from action is fundamental, I do not believe we can evade responsibility for hostile and destructive feelings and wishes. People cannot feel good about themselves when they are full of resentment, envy and hate. Part of the therapeutic task involves helping people transcend and creatively transform their destructiveness in favor of gratitude, creativity and love.

Kierkegaard tells us about the inevitability of existential guilt. He points to a kind of catch-22: if I fail to develop my potential for growth as a human being, I am failing myself and I will suffer existential guilt for this. On the other hand, if I do develop my potentials I risk growing away from or beyond others with whom I am in relationshipfamily members, a spouse-and they may experience my growth as a betrayal. Hence, I am guilty for growing and not growing. Here we have a type of existential guilt that is an inevitable part of the human condition. Psychoanalysis has largely failed to integrate these existential insights.

In the face of the many varieties of anxiety and guilt we employ a range of ego defense mechanisms, some more primitive and others more advanced, some more characteristic of PS, paranoid-schizoid functioning, and others more characteristic of $\mathrm{D}$, depressive/reparative functioning. Among the latter, the neurotic defenses, are repression, suppression, displacement, substitution, sublimation, rationalization, intellectualization, reaction-formation, etc. Among the more primitive defenses are splitting, projection, projective identification, denial, manic defenses and others. In addition to Anna Freud's (1936) classic work on defense mechanisms, more recent work, such as that by Vaillant (1992), may be consulted on this topic. 
(C)2021 Donald Carveth

dcarveth@gmail.com

\section{References}

Akhtar, S. (Ed.) (2013). Guilt: Origins, Manifestations, and Management. New York: Jason Aronson.

Barnett, B. (2007). You Ought To! A Psychoanalytic Study of the Superego and Conscience. Psychoanalytic Ideas Series, Wise, I. and Williams, P. (Eds.), Parsons, M. (Foreword). London: The Institute of Psychoanalysis and Karnac Books.

Bion, W.R. (1962). Learning From Experience. London: Heinemann.

Brenner, C. (1982). The Mind In Conflict. New York: International Universities Press

Buber, M. (1965). Guilt and guilt-feelings. In M. Friedman (Trans. \& Ed.), The Knowledge of Man: Selected Essays. New York: Harper \& Row, chapter 6, pp. 121-148.

Carveth, D. (2013). The Still Small Voice: Psychoanalytic Reflections on Guilt and Conscience. London: Karnac.

Frattaroli, E. (2013). Reflections on the absence of morality in psychoanalytic theory and practice. In: S. Akhtar (Ed.), Guilt: Origins, Manifestations, and Management. New York: Jason Aronson.

Freud, A. (1936). The Ego and the Mechanisms of Defence. New York: Inter-national Universities Press, 1966.

Freud, S. (1900). The Interpretation of Dreams. The Standard Edition of the Complete Psychological Works of Sigmund Freud, Vols, 4-5. London: Hogarth Press.

Freud, S. (1901). The Psychopathology of Everyday Life, S.E.., 6: 1-296.

Freud, S. (1911). Formulations on the Two Principles of Mental Functioning. S.E., 12: 213-226

Freud, S. (1915). Repression. S.E., 14: 141-158.

Freud, S. (1916). Anxiety. Lecture 25. Introductory Lectures on Psycho-analysis (Part 2). S.E., 16: 391-411.

Freud, S. (1923). The ego and the id. S.E., 19: 1-66.

Freud, S. (1926). Inhibitions, Symptoms and Anxiety. S.E., 20: 75-126.

Freud, S. (1933). Lecture 32. Anxiety and Instinctual Life. New introductory lectures on Psycho-analysis. S.E., 22: 80-135. 
Fromm, E. (1941). Escape from Freedom. New York: Holt, Rinehart and Winston.

Hughes, J.M. (2008). Guilt and Its Vicissitudes: Psychoanalytic Reflections on Morality. London: Routledge.

Jones, E. (1955). Sigmund Freud Life and Work, Volume Two: Years of Maturity 1901-1919. London: The Hogarth Press.

Kierkegaard, S. (1843). Fear and Trembling. Hannay, A. (Trans. \& Intro.). London: Penguin, 1985.

Kierkegaard, S. (1844). The Concept of Anxiety. Hannah, A. (Trans. \& Intro.) Londoon: Penguin, 2014.

Kierkegaard, S. (1849). The Sickness Unto Death. Hannay, A. (Trans.). London: Penguin, 1989.

Klein, M. (1946). Notes on some schizoid mechanisms. In: The Writings of Melanie Klein, Vol. 3. London: Hogarth Press, 1975, pp. 186-198.

Klein, M. (1948). A contribution to the theory of anxiety and guilt. International Journal of PsychoAnalysis 29: 114-123.

Lacan, J. (2002). Écrits: The First Complete Edition in English. Trans. B. Fink in collaboration with H. Fink and R. Grigg. New York: Norton.

Lasch, C. (1979). The Culture of Narcissism: American Life in an Age of Diminishing Expectations. New York: Warner.

Margolis, D. (1996). Freud and His Mother. Northvale, NJ: Aronson.

May, U. (2001). Abraham's discovery of the 'bad mother': A contribution to the history of the theory of depression. International Journal of Psychoanalysis, 82, 283-305.

Racker, H. (1957). The meaning and uses of countertransference. Psa. Q., 26: 303-357.

Rank, O. (1924). The Trauma of Birth. New York: Routledge, 2014.

Reiner, A. (2009). The Quest for Conscience and the Birth of the Mind. Foreword J. Grotstein. London: Karnac Books.

Sartre, J.-P. (1943). Being and Nothingness: A Study in Phenomenological Ontology. Trans. H.E. Barnes. New York: Philosophical Library, 1953.

Vaillant, G. (1992). Ego Mechanisms of Defence: A Guide for Clinicians and Researchers. New York: American Psychiatric Publishing.

Winnicott, D.W. (1963). The development of the capacity for concern. In: The Maturational Processes and the Facilitating Environment. London: Hogarth, 1965, 73-82. 